\title{
Implementation of an infection prevention bundle is associated with reduced surgical site infections in cranial neurosurgery
}

\author{
Samuel L. Rubeli, MD, ${ }^{1}$ Donato D’Alonzo, MD, ${ }^{2}$ Beate Mueller, ${ }^{1}$ Nicole Bartlomé, MPH, ${ }^{1}$ \\ Hans Fankhauser, PhD, ${ }^{3}$ Evelin Bucheli, MD, ${ }^{1}$ Anna Conen, MD, MSc, ${ }^{1}$ Javier Fandino, MD, ${ }^{2}$ and \\ Christoph A. Fux, MD'
}

Departments of ${ }^{1}$ Infectious Diseases and Hospital Hygiene, ${ }^{2}$ Neurosurgery, and ${ }^{3}$ Microbiology, Kantonsspital Aarau, Switzerland

\begin{abstract}
OBJECTIVE The objective of this study was to quantify surgical site infection (SSI) rates after cranial neurosurgery in a tertiary care hospital, identify risk factors for SSI, and evaluate the impact of standardized surveillance and an infection prevention bundle (IPB).
\end{abstract}

METHODS The authors compared SSI rates during 7 months before and after the intervention. The IPB included standardized patient preparation, perioperative antibiotic/antiseptic use, barrier precautions, coaching of surgeons, and the implementation of a specialized technical operation assistant team.

RESULTS Three hundred twenty-two unselected consecutive patients were evaluated before the IPB, and 296 were evaluated after implementation. Infection rates after 1 year decreased from $7.8 \%(25 / 322)$ to $3.7 \%(11 / 296, p=0.03)$ with similar mortality rates $(14.7 \%$ vs $13.8 \%, p=0.8)$. The isolated bacteria included Staphylococcus aureus $(42 \%)$, Cutibacterium acnes (22\%), and coagulase-negative staphylococci (14\%). Organ/space infections dominated with 67\%, and mostly consisted of subdural empyema and meningitis/ventriculitis. Among the 36 SSIs, 13 (36\%) occurred during hospitalization, and 29 (81\%) within the first 3 months of follow-up. In multivariable analysis including established risk factors described in the literature, non-CNS neoplasia (odds ratio [OR] 3.82, 95\% confidence interval [CI] 1.39-10.53), postoperative bleeding (OR 4.09,1.44-11.62), operations performed by or under supervision of a senior faculty surgeon (OR $0.38,0.17-0.84$ ), and operations performed after the implementation of standardized surveillance and an IPB (OR $0.38,0.17-0.85)$ significantly influenced the infection rate.

CONCLUSIONS The introduction of an IPB combined with routine surveillance and personal feedback was associated with a $53 \%$ reduced infection rate. The lower infection rates of senior faculty and the strong association between postoperative bleeding and infection underline the importance of both surgical experience as well as thorough supervision and coaching of younger surgeons.

https://thejns.org/doi/abs/10.3171/2019.5.FOCUS19272

KEYWORDS infection prevention bundle; postoperative bleeding; risk factors for surgical site infections; surgical experience

$\mathrm{P}$ OSTOPERATIVE surgical site infections (SSIs) are among the most frequent and costly healthcare-associated infections..$^{20,44}$ Depending on the type of surgery and infection depth, SSIs increase mortality rates and prolong postoperative lengths of stay. ${ }^{4,13,38}$ In cranial neurosurgery, SSIs occur in $0.5 \%-7.2 \%$ of patients, frequently require reoperations and long-lasting antibiotic treatment, and are often life-threatening.
More than $50 \%$ of SSIs have been considered preventable using evidence-based strategies. ${ }^{42}$ The most widely used guidelines addressing prevention strategies were published by the Centers for Disease Control and Prevention (CDC) and the Society for Healthcare Epidemiology of America. ${ }^{3,6}$ Prevention measures range from adherence to standard principles of asepsis, i.e., timely administration of appropriate surgical antimicrobial prophylaxis (SAP)

ABBREVIATIONS ASA = American Society of Anesthesiologists; $\mathrm{CDC}=$ Centers for Disease Control and Prevention; $\mathrm{Cl}=$ confidence interval; CoNS = coagulase-negative staphylococci; ICP = intracranial pressure; IPB = infection prevention bundle; NNIS = National Nosocomial Infection Surveillance; OR = odds ratio; PEEK = polyetheretherketone; PMMA = polymethylmethacrylate; SAP = surgical antimicrobial prophylaxis; SSI = surgical site infection.

SUBMITTED March 30, 2019. ACCEPTED May 13, 2019.

INCLUDE WHEN CITING DOI: 10.3171/2019.5.FOCUS19272. 
or the minimization of operative time, to the maintenance of intraoperative euglycemia and normothermia (for improved tissue oxygenation). The implementation of perioperative infection prevention bundles (IPBs), which includes a selection of individual evidence-based targets to reduce SSI, has proven particularly effective. IPBs have reduced SSI rates for a broad range of interventions ${ }^{34}$ including colon, ${ }^{40,45}$ cardiac, and orthopedic surgery, ${ }^{27}$ but also cranial neurosurgery. ${ }^{17,23,26}$ In all of the above-mentioned guidelines, standardized surveillance with immediate personal feedback to surgeons is considered key, as this measure by itself reduces SSI. ${ }^{12}$

In cranial neurosurgery, male sex, age greater than 60 years, smoking, longer preoperative stay, an operative duration longer than 3 hours, emergency or repetitive surgery, contaminated surgery, the use of implants, and CSF leakage or CSF drainage have been identified as independent risk factors for SSI. ${ }^{1,16,21,22,26,38,39}$ The most frequent organisms found in neurosurgical SSI were Staphylococcus aureus, Cutibacterium acnes, and coagulase-negative staphylococci (CoNS). ${ }^{1,15,16,23,31,39}$ The identification of skin flora as the main source of infection directed the focus of our IPB and guided the selection of interventions.

The aims of our study were to quantify SSI rates in cranial neurosurgery at our tertiary care center and quantify the impact of individual risk factors for SSI. Furthermore, we aimed to evaluate whether standardized SSI surveillance combined with the implementation of an IPB can reduce SSI.

\section{Methods}

\section{Data Collection and Definitions}

The study was performed at the Department for Neurosurgery of the Kantonsspital Aarau Switzerland, with a catchment area of approximately one million inhabitants and 2000 surgical procedures performed per year. Based on a standardized case report form, SSI data were retrospectively collected from all patients undergoing cranial neurosurgical interventions between January and July 2012 as well as between January and July 2014, which is before and after the implementation of standardized surveillance and the IPB. We included standard neurosurgical procedures such as trepanation, craniotomy/craniectomy, cranioplasty, transsphenoidal surgery, and ventriculoperitoneal shunt (VPS) insertion. All SSIs up to 1 year after hospital discharge were collected based on hospital records, given that referral for infectious complications to other clinics is extremely rare.

The primary endpoint was the SSI rate after 3 months and 1 year for interventions without and with foreign material implants, respectively..$^{18}$ SSI was defined according to the CDC and classified into one of three groups: 1) superficial incisional (e.g., skin and soft-tissue infection), 2) deep incisional (e.g., bone flap osteitis), and 3) organ/space (e.g., subdural empyema, brain abscess, meningitis). ${ }^{29}$ For all infections, we determined the time to SSI occurrence, the causative pathogens including their susceptibility pattern, as well as the 3-month and 1-year mortality rates.

\section{The IPB}

The IPB addressed established risk factors for $\mathrm{SSI}^{3,6}$ and was introduced in January 2013. It included 10 interventions addressing 6 different topics. Interventions consisted of reinforcing existing standards as well as introducing new ones (indicated in italics):

- Patient preparation: hair removal using clippers instead of razors. ${ }^{3,6,24}$

- Antibiotic and antiseptic use: SAP with $1.5 \mathrm{~g}$ of intravenous cefuroxime ( $3 \mathrm{~g}$ for body weight $>80 \mathrm{~kg}$ ) within 1 hour before incision and dose repetition if duration of surgery exceeded 4 hours, $;, 22,43$ skin disinfection with alcohol-based solutions (except for transsphenoidal surgery) before three-point skull clamp placement (chrome steel or carbon radiolucent) ${ }^{28}$ disinfection of the incision border directly after incision and before wound closure to eliminate bacteria newly exposed or regrown in hair follicles and dermal glands.

- Barrier precautions: complete coverage of surgeons' hair on head and face; gloves exchanged every 2 hours and before implantation of foreign material ${ }^{33}$ minimization of traffic and door openings in the operating theater, ${ }^{7,36}$

- Surgeons' coaching: gentle tissue handling and thorough mechanical hemostasis techniques such as irrigation, bipolar coagulation, and slight compression. Limited use of hemostatic agents and foreign materials. ${ }^{3,6,9,32}$

- Specialized technical operation assistant team for neurosurgery.

- Standardized surveillance and feedback: Routine monitoring of bundle compliance in the operating theater with personal feedback by members of the hospital hygiene team; routine discussion of perioperative complications, in particular infections and postoperative bleeding and their prevention measures, by the head of the department.

\section{Statistical Analysis}

We used Stata/SE (version 12, StataCorp LP) for statistical analyses and Kaplan-Meier curves. Differences between SSI and non-SSI as well as between the pre- and post-IPB period were evaluated using chi-square tests for categorical variables and Wilcoxon rank-sum tests for continuous variables. In cases of small sample sizes, Fisher's exact test was performed. Univariable and multivariable logistic regression analyses were used to identify patient- and procedure-related risk factors for SSI. Results are presented as odds ratios (ORs) with $95 \%$ confidence intervals (CIs).

Patient characteristics included age, sex, BMI, indication for surgery, cranial trauma within 4 weeks before surgery, American Society of Anesthesiologists (ASA) classification of physical status, perioperative corticosteroids (i.e., a prednisone equivalent $\geq 10 \mathrm{mg}$ ), non-CNS malignancy, diabetes mellitus, and the National Nosocomial Infection Surveillance (NNIS) risk index (NNIS score ranging from 0 to 3 : 1 point each for wound class $>$ 2 , ASA score $>2$ and duration of surgery $>$ T-time [standard operative duration]; according to the CDC, T-time for craniotomy was set at 4 hours, and for VPS at 2 hours). ${ }^{14,18}$

Procedural characteristics included mode and duration of surgery; elective and clean surgery (i.e., Altemeier 
wound class I); ${ }^{2}$ use of wound and CSF drainages as well as intracranial pressure (ICP) monitoring devices, with their respective indwelling times; hemostatic agents used (TachoSil [Takeda Pharma AG], Spongostan, and fibrin glue); foreign material used, including bone fixation devices, synthetic cranioplasty (polymethylmethacrylate [PMMA] or polyetheretherketone [PEEK] plastic), nonautologous dural substitutes (xenografts and synthetic materials) and VPSs; and adequate SAP and postoperative bleeding. Operations performed by or under supervision of 4 senior faculty (i.e., those with $\geq 5$ years after board certification) were compared to 9 junior faculty surgeons (i.e., those with $<5$ years after board certification).

For multivariable regression analysis all statistically significant predictors in univariable analyses were included, as well as the most important risk factors for SSI described in the literature irrespective of their performance in univariable analysis. These risk factors included older age, $\mathrm{BMI} \geq 30 \mathrm{~kg} / \mathrm{m}^{2}$, NNIS score $\geq 1$, emergency surgery, inadequate SAP (i.e., not meeting the standard for the IPB defined above), foreign material implants, and the use of external CSF and wound drains. 3 , $14,16,21,22,29,38$

The Swiss Ethics Committee on research involving humans granted permission for the study.

\section{Results}

\section{Baseline Characteristics}

A total of 618 cranial neurosurgical interventions in 520 patients were analyzed, $322(52.1 \%)$ in the pre-IPB period and $296(47.9 \%)$ in the post-IPB period (Table 1). Head trauma and cranioplasty were significantly more frequent in the pre-IPB period, whereas clean surgery and TachoSil-assisted hemostasis were more frequent after the IPB. SAP was documented for 574 interventions (92.9\%), consisting of cefuroxime in $98.5 \%$. For 113 interventions (18.3\%), SAP was considered inadequate because it was not documented, concluded only after skin incision, or not repeated for surgeries of more than 4 hours duration. More operations were performed by or under the supervision of a senior faculty member before the IPB period $(62.7 \%$ vs $51.7 \%, \mathrm{p}=0.006$ ). A postdischarge follow-up at 3 months and 1 year (for patients with implants) was documented in $98.9 \%$ and $84.6 \%$, respectively.

\section{Primary Outcomes}

Overall, 36 SSIs occurred with a median time to infection of 20 days (IQR 8.5-45.5 days). Twenty-nine SSIs $(80.6 \%)$ were detected within 3 months after surgery (Table 2). The infection rate significantly decreased from $7.8 \%$ to $3.7 \%$ between the pre- and post-IPB period $(\mathrm{p}=0.03)$. Post-IPB SSI rates for junior faculty decreased from $14.6 \%$ to $4.3 \%$, while SSI rates remained low in senior faculty $(4.5 \%$ vs $3.3 \%)$. While superficial and deep SSI accounted for $11.1 \%$ and $22.2 \%$, respectively, the majority (66.7\%) were organ/space infections. SSI-free survivals overall and stratified for localization of the infection are illustrated in Fig. 1. The anatomical localization of the 36 SSIs was as follows: 6 patients $(16.7 \%)$ had skin or soft-tissue infections at the incision site, 5 had autologous bone flap infections (13.9\%), and 1 had a synthetic cranioplasty-associated in- fection. Subdural empyema was described in 10 patients (27.8\%) and meningitis or ventriculitis in 7 (19.4\%), 3 of which were associated with an external ventricular drain and 1 with a VPS. An epidural abscess was found in 5 (13.9\%) patients, and a brain abscess in 2 (5.6\%).

The most frequently detected organisms were $S$. aureus (41.7\%), followed by C.acnes (22.2\%) and CoNS (13.9\%). Only 3 isolates (2 CoNS and 1 Pseudomonas aeruginosa) were nonsusceptible to SAP with cefuroxime (Table 3).

All patients with SSI received systemic antibiotic therapy, and $75 \%$ underwent surgical revision. Among the 30 infections associated with foreign material, the implant was removed or exchanged in $83.3 \%$. The overall mortality rate was $9.1 \%$ after 3 months and $14.3 \%$ after 1 year, without a significant difference between the pre- and post-IPB period (Table 2). Patients with SSI had a 1-year mortality rate of $24 \%$.

\section{Risk Factors for SSI}

Considering the type of intervention, trepanation showed the highest infection rate with 7.0\%, and VPS the lowest with $1.6 \%$ (Table 4). Among the indications for surgery, most infections occurred in patients with brain metastases (12.8\%), followed by subdural hematoma (10.2\%), whereas the lowest infection rate was found for patients with hydrocephalus (1.6\%).

In univariable logistic regression analyses, diabetes mellitus, non-CNS malignancy, subdural hematoma, use of Spongostan, and postoperative bleeding were significantly associated with SSI (Table 4). With ORs of 3.5 (95\% CI 0.82-14.74) and 2.6 (95\% CI 0.95-7.11), respectively, an NNIS score $\geq 1$ and brain metastases also showed trends for a higher infection rate. Conversely interventions performed by senior faculty surgeons as head surgeon or first assistant were associated with significantly lower infection rates. In multivariable analysis, non-CNS malignancy (OR $3.82,95 \%$ CI 1.39-10.53) and postoperative bleeding (OR $4.09,95 \%$ CI 1.44-11.62) remained independently associated with SSI, while the post-IPB period (OR $0.38,95 \%$ CI $0.17-0.85$ ) and senior faculty surgeons as head surgeon or first assistant showed a lower SSI risk (OR 0.38, 95\% CI 0.17-0.84; Table 4). For sensitivity analyses, we included all parameters with significant differences or trends for differences at baseline, but no significant univariate associations with SSI, in the multivariate analysis (i.e., head trauma, clean surgery, TachoSil use, cranioplasty, artificial cranioplasty, ICP monitoring, and VPS). None of these parameters showed a significant effect ( $\mathrm{p}$ values between 0.24 and 0.49 ) or altered the correlation of non-CNS malignancy, postoperative bleeding, junior staff, and pre-IPB period with higher SSIs.

The correlation between the overall number of operations performed by an individual surgeon or technical operation assistant (plotted on the x-axis) and his or her cumulative infection rate (plotted on the y-axis) is shown in Fig. 2A and B, respectively. For both professions, we illustrate an inverse correlation between the number of operations and infection rates that became less important post-IPB (Fig. 2, full circles) as compared to pre-IPB (Fig. 2 , open circles), particularly for the individuals with a low number of interventions. 
TABLE 1. Baseline characteristics of patients undergoing cranial neurosurgery with a comparison of the periods before and after implementation of an IPB

\begin{tabular}{|c|c|c|c|}
\hline Patient Characteristics & Pre-IPB $(n=322)$ & Post-IPB (n = 296) & $p$ Value \\
\hline Median age (IQR), yrs & $59(47-73)$ & $61(48-71)$ & 0.44 \\
\hline Female sex, $\mathrm{n}(\%)$ & $153(47.5)$ & $144(48.7)$ & 0.78 \\
\hline $\mathrm{BMI} \geq 30 \mathrm{~kg} / \mathrm{m}^{2}, \mathrm{n}(\%)$ & $48(14.9)$ & $40(13.5)$ & 0.62 \\
\hline Diabetes mellitus, $\mathrm{n}(\%)$ & $25(7.8)$ & $27(9.1)$ & 0.54 \\
\hline Periop corticosteroids, $\mathrm{n}(\%)^{*}$ & $80(24.8)$ & $81(27.4)$ & 0.48 \\
\hline Non-CNS malignancy, $\mathrm{n}(\%)$ & $25(7.8)$ & $27(9.1)$ & 0.54 \\
\hline Head trauma, $n(\%)$ & $69(21.4)$ & $42(14.2)$ & 0.02 \\
\hline ASA score >2, n (\%) & $201(62.4)$ & $190(64.2)$ & 0.65 \\
\hline Median NNIS score, (IQR)† & $1(1)$ & $1(1)$ & 0.24 \\
\hline \multicolumn{4}{|l|}{ Indication for op, $\mathrm{n}(\%)$} \\
\hline Intracerebral hemorrhage & $46(14.3)$ & $41(13.9)$ & 0.88 \\
\hline Subdural hematoma & $58(18.0)$ & $50(16.9)$ & 0.71 \\
\hline Neurovascular malformation $\ddagger$ & $50(15.5)$ & $53(17.9)$ & 0.43 \\
\hline Primary CNS neoplasia§ & $103(32)$ & $81(27.4)$ & 0.21 \\
\hline CNS metastases & $17(5.3)$ & $22(7.4)$ & 0.27 \\
\hline Hydrocephalus & $28(8.7)$ & $35(11.8)$ & 0.2 \\
\hline Cranial infection & $21(6.5)$ & $14(4.7)$ & 0.34 \\
\hline \multicolumn{4}{|l|}{ Procedural characteristics } \\
\hline \multicolumn{4}{|l|}{ Type of op, n (\%) } \\
\hline Trepanation & $89(27.6)$ & $83(28)$ & 0.91 \\
\hline Craniotomy & $175(54.3)$ & $159(53.7)$ & 0.88 \\
\hline Cranioplasty & $17(5.3)$ & $7(2.4)$ & 0.06 \\
\hline Transsphenoidal surgery & $14(4.3)$ & $11(3.7)$ & 0.69 \\
\hline Ventriculoperitoneal shunt & $27(8.4)$ & $36(12.2)$ & 0.12 \\
\hline Clean op, n (\%)ף & $277(86.0)$ & $272(91.9)$ & 0.02 \\
\hline Median duration of op (IQR), mins & $170(80-265)$ & $150(70-260)$ & 0.48 \\
\hline Elective surgery, $\mathrm{n}(\%)$ & $175(54.3)$ & $151(51)$ & 0.41 \\
\hline Adequate SAP, $\mathrm{n}(\%)$ & $264(82.0)$ & $241(81.4)$ & 0.86 \\
\hline Use of hemostatic agents, $n(\%)$ & $191(59.3)$ & $176(59.5)$ & 0.97 \\
\hline TachoSil & $92(28.6)$ & $133(44.9)$ & $<0.001$ \\
\hline Spongostan & $29(9)$ & $16(5.4)$ & 0.09 \\
\hline Fibrin glue & $161(50)$ & $147(49.7)$ & 0.93 \\
\hline Foreign material implants, $\mathrm{n}(\%)$ & $241(74.8)$ & $212(71.6)$ & 0.37 \\
\hline Bone fixation & $167(51.9)$ & $156(52.7)$ & 0.84 \\
\hline Nonautologous dural substitute & $95(29.5)$ & $79(26.7)$ & 0.44 \\
\hline Synthetic cranioplasty** & $26(8.1)$ & $16(5.4)$ & 0.02 \\
\hline Ventriculoperitoneal shunt & $26(8.1)$ & $36(12.2)$ & 0.09 \\
\hline Wound drainage, $\mathrm{n}(\%)$ & $163(50.6)$ & $151(51)$ & 0.92 \\
\hline External CSF drainage, $\mathrm{n}(\%)$ & $38(11.8)$ & $38(12.8)$ & 0.7 \\
\hline Median duration (IQR), days & $5(3-9.5)$ & $6(2.5-15)$ & 0.43 \\
\hline ICP monitoring device, $\mathrm{n}(\%)$ & $29(9)$ & $15(5.1)$ & 0.06 \\
\hline Median duration (IQR), days & $3(1-4)$ & $2(2-6)$ & 0.84 \\
\hline Senior faculty, $\mathrm{n}(\%) \dagger \dagger$ & $202(62.7)$ & $153(51.7)$ & 0.006 \\
\hline Junior faculty, n (\%)†† & $110(34.2)$ & $141(47.6)$ & 0.001 \\
\hline Postop bleeding, n (\%) & $21(6.5)$ & $21(7.1)$ & 0.78 \\
\hline Previous op, $\mathrm{n}(\%)$ & $97(30.1)$ & $91(30.7)$ & 0.87 \\
\hline
\end{tabular}


TABLE 1. Baseline characteristics of patients undergoing cranial neurosurgery with a comparison of the periods before and after implementation of an IPB

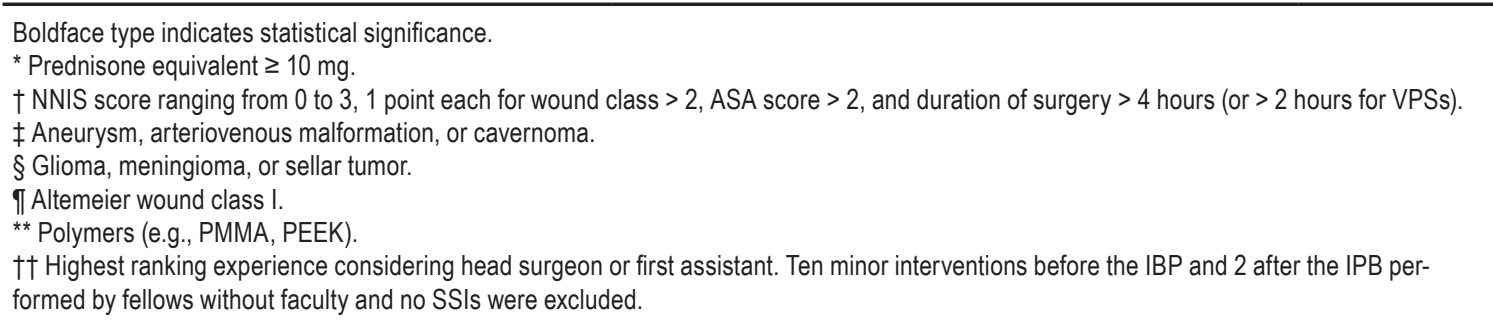

\section{Discussion}

The introduction of an IPB combined with standardized surveillance and feedback in cranial neurosurgery was followed by a significant $53 \%$ reduction in SSI, from $7.8 \%$ to $3.7 \%$. The high prevalence of deep and organ/ space infections $(88.9 \%)$ with their frequent need for surgical revisions $(75 \%)$ as well as the $24 \%$ mortality rate associated with an SSI emphasize the high impact of SSI in cranial neurosurgery. Therefore, prevention strategies including IPB are essential.

Perioperative IPBs are established as cost-effective interventions to prevent SSI ${ }^{34}$ For colon, cardiac, and orthopedic surgery, IPBs have reduced SSI rates by $40 \%-50 \%$, which is in the range of our study. ${ }^{27,40,45}$ There exist only limited data about the efficacy of IPBs in cranial neurosurgery, providing contradictory results. In one study, SSIs after cranioplasty were significantly reduced from $23.8 \%$ to $2.8 \%$ using an IPB combining vancomycin SAP and postoperative wound decolonization and standardized dressings. ${ }^{23}$ Similarly, Liu et al. improved postcranioplasty infection rates from $10.5 \%$ to $1.8 \%$ using an IPB as well as active SSI monitoring. ${ }^{26}$ Both studies had remarkably high preintervention SSI rates and a low number of included patients (57 and 199, respectively), as compared to the 520 patients included in our study. Conversely, an IPB addressing perioperative glucose and body temperature control had no effect on SSI. ${ }^{16}$

Based on international guidelines ${ }^{3,6}$ and a literature review, our prevention bundle not only combined technical (e.g., hair clipping instead of shaving, strict alcohol-based disinfection) and process improvements (e.g., a specialized technical operation assistant team), but also reinforced the awareness of surgeons for strict barrier precautions and meticulous hemostasis. Similar to results in the literature, ${ }^{1,15,16,23,31,39}$ we found a high proportion of skin organisms causing SSI, justifying the focus of our IPB on timely SAP, skin disinfection, and barrier precautions. In addition, the low prevalence of cefuroxime resistance $(9.7 \%)$ supported its use for SAP.

\section{Surgical Site Infections}

The infection rate of $3.7 \%$ in the post-IPB period is in the range of the $0.5 \%-7.2 \%$ described in published large series of cranial neurosurgery. $1,11,15,21,22,31,38,39$ In contrast to many studies reporting mere in-hospital SSI rates, patients in our study were monitored for 1 year if an implant was in place, which in itself explains higher SSI rates. Also, our follow-up rates of $98.9 \%$ at 3 months and $84.6 \%$ at 1 year were higher than those reported in the literature. ${ }^{4,15,17,41}$ As $63.9 \%$ of our infections were detected postdischarge and $19.4 \%$ beyond 3 months of follow-up, a significant number of infections would have been missed with a shorter follow-up period.

Analyzing the risk factors for SSI provides insight into its pathophysiology. Non-CNS malignancy (OR 3.8, p = $0.01)$ may be a surrogate for well-established risk factors for SSI such as chemotherapy-induced neutropenia, radiation-induced tissue damage, or malnutrition with consecutive hypoalbuminemia. ${ }^{3,6,25}$ Diabetes mellitus, an established risk factor, showed a trend for higher SSI in multivariable analysis (OR 2.7, $\mathrm{p}=0.06$ ), which may be explained by associated immunodeficiency and impaired microcirculation..$^{30}$ With 10 of the 36 infections, subdural empyema was the most frequent SSI. The fact that 8 of 10 subdural empyemas originated from subdural hematoma and 5 of 10 were preceded by postoperative bleeding underlines the importance of hematoma in the pathophysiology of SSI. In regression analyses, both subdural hematoma and postoperative bleeding more than doubled the risk for

TABLE 2. SSI and mortality rates comparing the periods before and after implementation of an IPB

\begin{tabular}{lccc}
\hline \multicolumn{1}{c}{ Variable } & $\begin{array}{c}\text { Pre-IPB } \\
(\mathrm{n}=322)\end{array}$ & $\begin{array}{c}\text { Post-IPB } \\
(\mathrm{n}=296)\end{array}$ & $\begin{array}{c}\mathrm{p} \\
\text { Value }\end{array}$ \\
\hline Infections, $\mathrm{n}(\%)$ & & & \\
\hline In-hospital & $10(3.1)$ & $3(1.0)$ & 0.09 \\
\hline At 3 mos & $21(6.5)$ & $8(2.7)$ & 0.04 \\
\hline At 1 yr & $25(7.8)$ & $11(3.7)$ & 0.03 \\
\hline With implant & $21(6.5)$ & $9(3.0)$ & 0.04 \\
\hline Median days to occurrence (IQR) & $14(8-27)$ & $30(20-180)$ & \\
\hline Deaths, $\mathrm{n}(\%)$ & & & \\
\hline At 3 mos $(\mathrm{n}=514)$ & $24(8.7)$ & $23(9.7)$ & 0.7 \\
\hline At 1 yr $(\mathrm{n}=335)$ & $29(14.7)$ & $19(13.8)$ & 0.8 \\
\hline Type of SSI $(\mathrm{n}=36), \mathrm{n}(\%)$ & & & \\
\hline Superficial & $3(12.0)$ & $1(9.1)$ & 1.0 \\
\hline Deep & $4(16.0)$ & $4(36.4)$ & 0.21 \\
\hline Organ/space & $18(72.0)$ & $6(54.5)$ & 0.45 \\
\hline
\end{tabular}

Boldface type indicates statistical significance. 


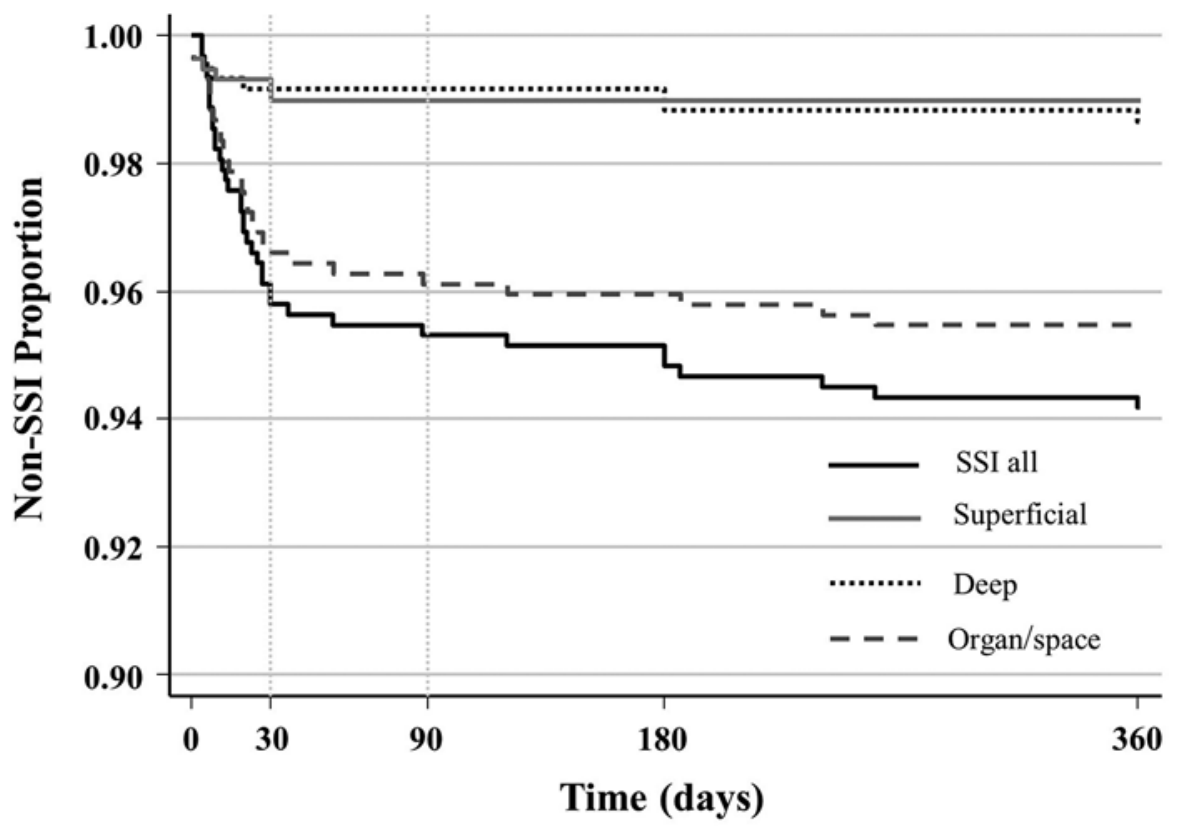

Number at risk

$\begin{array}{lll}618 & 589 & 588\end{array}$

FIG. 1. Kaplan-Meier curves for SSI-free survival by type of infection for the 36 infections identified during a 1-year follow-up. Twenty-six (72\%) and 29 (81\%) were detected within 1 and 3 months after surgery, respectively.

SSI. Postoperative bleeding due to tissue traumatization or insufficient hemostasis provides a perfect breeding ground for contaminating bacteria. Spongostan use significantly correlated with SSI in univariable analysis, and continued to show a strong trend (OR 2.63, 0.95-7.31) in multivariable analysis. Its reduced use in the post-IPB period might have contributed to fewer SSIs, possibly by lowering the risk for foreign material-associated biofilm infections. Alternatively, improved hemostasis post-IPB might have lowered the need for Spongostan. Unlike results in the literature, neither wound or external CSF drainage, although performed in $50.8 \%$ and $12.3 \%$, respectively, nor invasive ICP monitoring were associated with SSI in our study. ${ }^{6,38}$

\section{Senior and Junior Faculty}

Interventions performed or supervised by senior faculty surgeons showed significantly fewer infections than opera- tions performed by junior faculty (OR $0.38,95 \%$ CI $0.17-$ 0.84), although senior faculty performed the most difficult and long-lasting operations, which generally are associated with higher infection rates. This may also explain why trepanations - a relatively simple intervention mainly performed by junior faculty - had the highest infection rate. This underlines the importance of experience and surgical skills for SSI prevention. The predictive value of good surgical skills for lower SSI rates has impressively been demonstrated for laparoscopic surgery. ${ }^{8} \mathrm{~A}$ high degree of experience not only benefits the individual surgeon, but also the hospital. There is strong data correlating a high operative volume with better outcome, including lower mortality. ${ }^{19,37}$ In the study by Jafari et al., however, high surgical volume provided its maximal benefit only in combination with accreditation, a process requiring thorough standardization and defined procedures. ${ }^{19}$

TABLE 3. Pathogens causing SSls according to the type of infection

\begin{tabular}{cccccc}
\hline Pathogen & All SSI (\%) & Superficial & Deep & Organ/Space & Susceptibility to SAP (\%) \\
\hline Total detected, $\mathrm{n}(\%)$ & $31(100)$ & 2 & 9 & 20 & $28(90.3)$ \\
\hline S. aureus & $15(41.7)$ & 2 & 1 & 12 & $15(100)$ \\
\hline C. acnes & $8(22.2)$ & 0 & 4 & 4 & $8(100)$ \\
\hline CoNS & $5(13.9)$ & 0 & 2 & 3 & $1(60)$ \\
\hline S. gordonii & $1(2.8)$ & 0 & 0 & 1 & $1(50)$ \\
\hline Gram-negative* $^{*}$ & $2(5.6)$ & 0 & 2 & 0 & 5 \\
\hline Culture negative & $8(22.2)$ & 2 & 1 & 5 &
\end{tabular}

${ }^{*} P$. aeruginosa, Finegoldia magna. 
TABLE 4. Uni- and multivariable logistic regression analyses to determine risk factors for SSIs

\begin{tabular}{|c|c|c|c|c|c|c|}
\hline \multirow[b]{2}{*}{ Patient Characteristics } & \multirow[b]{2}{*}{$\begin{array}{c}\text { No SSI } \\
(n=582)\end{array}$} & \multirow[b]{2}{*}{ SSI $(n=36)$} & \multicolumn{2}{|l|}{ Univariable } & \multicolumn{2}{|l|}{ Multivariable } \\
\hline & & & OR $(95 \% \mathrm{Cl})$ & $\begin{array}{c}p \\
\text { Value }\end{array}$ & OR $(95 \% \mathrm{Cl})$ & $\begin{array}{c}p \\
\text { value }\end{array}$ \\
\hline Median age (IQR), yrs & $60(47-71)$ & $61(48.5-74)$ & $1.13(0.92-1.38)^{*}$ & 0.35 & $0.89(0.69-1.14)^{*}$ & 0.35 \\
\hline Female sex, $\mathrm{n}(\%)$ & $281(48.3)$ & $16(44.4)$ & $0.86(0.44-1.69)$ & 0.66 & & \\
\hline $\mathrm{BMI} \geq 30 \mathrm{~kg} / \mathrm{m}^{2}, \mathrm{n}(\%)$ & $80(13.8)$ & $8(22.2)$ & $1.79(0.79-4.01)$ & 0.21 & $1.87(0.75-4.68)$ & 0.18 \\
\hline Diabetes mellitus, n (\%) & $45(7.7)$ & $7(19.4)$ & $2.88(1.2-6.94)$ & 0.02 & $2.66(0.96-7.32)$ & 0.06 \\
\hline Periop corticosteroids, n (\%) & $155(26.6)$ & $6(16.7)$ & $0.55(0.22-1.35)$ & 0.24 & & \\
\hline Non-CNS malignancy, n (\%) & $44(7.6)$ & $7(19.4)$ & $2.95(1.22-7.12)$ & 0.02 & $3.82(1.39-10.53)$ & 0.01 \\
\hline Head trauma, $\mathrm{n}(\%)$ & $103(17.7)$ & $8(22.2)$ & $1.33(0.59-3.0)$ & 0.5 & & \\
\hline NNIS score $\geq 1, n(\%)$ & $483(83)$ & $34(94.4)$ & $3.5(0.82-14.74)$ & 0.1 & $2.46(0.53-11.42)$ & 0.25 \\
\hline \multicolumn{7}{|l|}{ Indication for op, $\mathrm{n}(\%)$} \\
\hline Intracerebral hemorrhage & $84(14.4)$ & $3(8.3)$ & $0.54(0.16-1.8)$ & 0.46 & & \\
\hline Subdural hematoma & $97(16.7)$ & $11(30.6)$ & $2.2(1.05-4.62)$ & 0.03 & $1.4(0.41-4.8)$ & 0.59 \\
\hline Neurovascular malformation & $96(16.5)$ & 7 (19.4) & $1.22(0.52-2.87)$ & 0.65 & & \\
\hline Primary CNS neoplasia & $175(30.1)$ & $9(25)$ & $0.78(0.36-1.68)$ & 0.58 & & \\
\hline CNS metastases & $34(5.8)$ & $5(13.9)$ & $2.6(0.95-7.11)$ & 0.07 & & \\
\hline Hydrocephalus & $62(10.7)$ & $1(2.8)$ & $0.24(0.03-1.78)$ & 0.16 & & \\
\hline Cranial infection & $34(5.8)$ & $1(2.8)$ & $0.46(0.61-3.46)$ & 0.71 & & \\
\hline \multicolumn{7}{|l|}{ Procedural characteristics } \\
\hline \multicolumn{7}{|l|}{ Type of op, n (\%) } \\
\hline Trepanation & $160(27.5)$ & $12(33.3)$ & $1.32(0.64-2.7)$ & 0.45 & & \\
\hline Craniotomy & $314(54)$ & $20(55.6)$ & $1.07(0.54-2.1)$ & 0.85 & & \\
\hline Cranioplasty & $21(3.6)$ & $3(8.3)$ & $2.43(0.69-8.56)$ & 0.16 & & \\
\hline Transsphenoidal op & $25(4.3)$ & 0 & & 0.39 & & \\
\hline VPS & $62(10.7)$ & $1(2.8)$ & $0.24(0.03-1.78)$ & 0.16 & & \\
\hline Clean surgery, n (\%) & $515(88.5)$ & $34(94.4)$ & $2.2(0.52-9.42)$ & 0.27 & & \\
\hline Median duration of op (IQR), mins & $160(75-260)$ & $170(80-280)$ & 1.0 & 1.0 & & \\
\hline Elective op, n (\%) & $308(52.9)$ & $18(50)$ & $0.89(0.45-1.74)$ & 0.73 & $1.32(0.51-3.45)$ & 0.57 \\
\hline Adequate SAP, n (\%) & $475(81.6)$ & $30(83.3)$ & $1.13(0.46-2.77)$ & 0.8 & $1.14(0.41-3.2)$ & 0.81 \\
\hline Use of hemostatic agents, $n(\%)$ & $344(59.1)$ & $23(63.9)$ & $1.22(0.61-2.46)$ & 0.57 & & \\
\hline TachoSil & $214(36.8)$ & $11(30.6)$ & $0.76(0.37-1.57)$ & 0.45 & & \\
\hline Spongostan & $37(6.4)$ & $8(22.2)$ & $4.21(1.79-9.88)$ & 0.003 & $2.63(0.95-7.31)$ & 0.06 \\
\hline Fibrin glue & $289(49.7)$ & $19(52.8)$ & $1.13(0.58-2.22)$ & 0.72 & & \\
\hline Foreign material implants, n (\%) & $426(73.2)$ & $27(75)$ & $1.1(0.51-2.39)$ & 0.81 & $1.33(0.49-3.6)$ & 0.57 \\
\hline Bone fixation & $302(51.9)$ & $21(58.3)$ & $1.3(0.66-2.57)$ & 0.45 & & \\
\hline Nonautologous dural substitute & $162(27.8)$ & $12(33.3)$ & $1.3(0.63-2.65)$ & 0.48 & & \\
\hline Synthetic cranioplasty & $38(6.5)$ & $4(11.1)$ & $1.79(0.6-5.32)$ & 0.3 & & \\
\hline VPS & $61(10.5)$ & $1(2.8)$ & $0.24(0.03-1.81)$ & 0.25 & & \\
\hline Wound drainage, n (\%) & $291(50)$ & $23(63.9)$ & $1.77(0.88-3.56)$ & 0.11 & $1.34(0.54-3.32)$ & 0.53 \\
\hline External CSF drainage, $\mathrm{n}(\%)$ & $72(12.4)$ & 4 (11.1) & $0.89(0.3-2.58)$ & 1.0 & $1.65(0.4-6.72)$ & 0.49 \\
\hline ICP monitoring device, $\mathrm{n}(\%)$ & $42(7.2)$ & $2(5.6)$ & $0.76(0.18-3.26)$ & 1.0 & & \\
\hline Senior vs junior faculty, n (\%) & $341(58.6)$ & $14(38.9)$ & $0.45(0.23-0.9)$ & 0.02 & $0.38(0.17-0.84)$ & 0.02 \\
\hline Postop bleeding, n (\%) & $34(5.8)$ & $8(22.2)$ & $4.6(1.95-10.87)$ & 0.002 & $4.09(1.44-11.62)$ & 0.008 \\
\hline Previous op, n (\%) & $179(30.8)$ & $9(25)$ & $0.75(0.35-1.63)$ & 0.58 & & \\
\hline Post-IPB vs pre-IPB, n (\%) & $285(49)$ & $11(30.6)$ & $0.46(0.22-0.95)$ & 0.03 & $0.38(0.17-0.85)$ & 0.02 \\
\hline
\end{tabular}

Boldface type indicates statistical significance.

* OR per 10 years. 

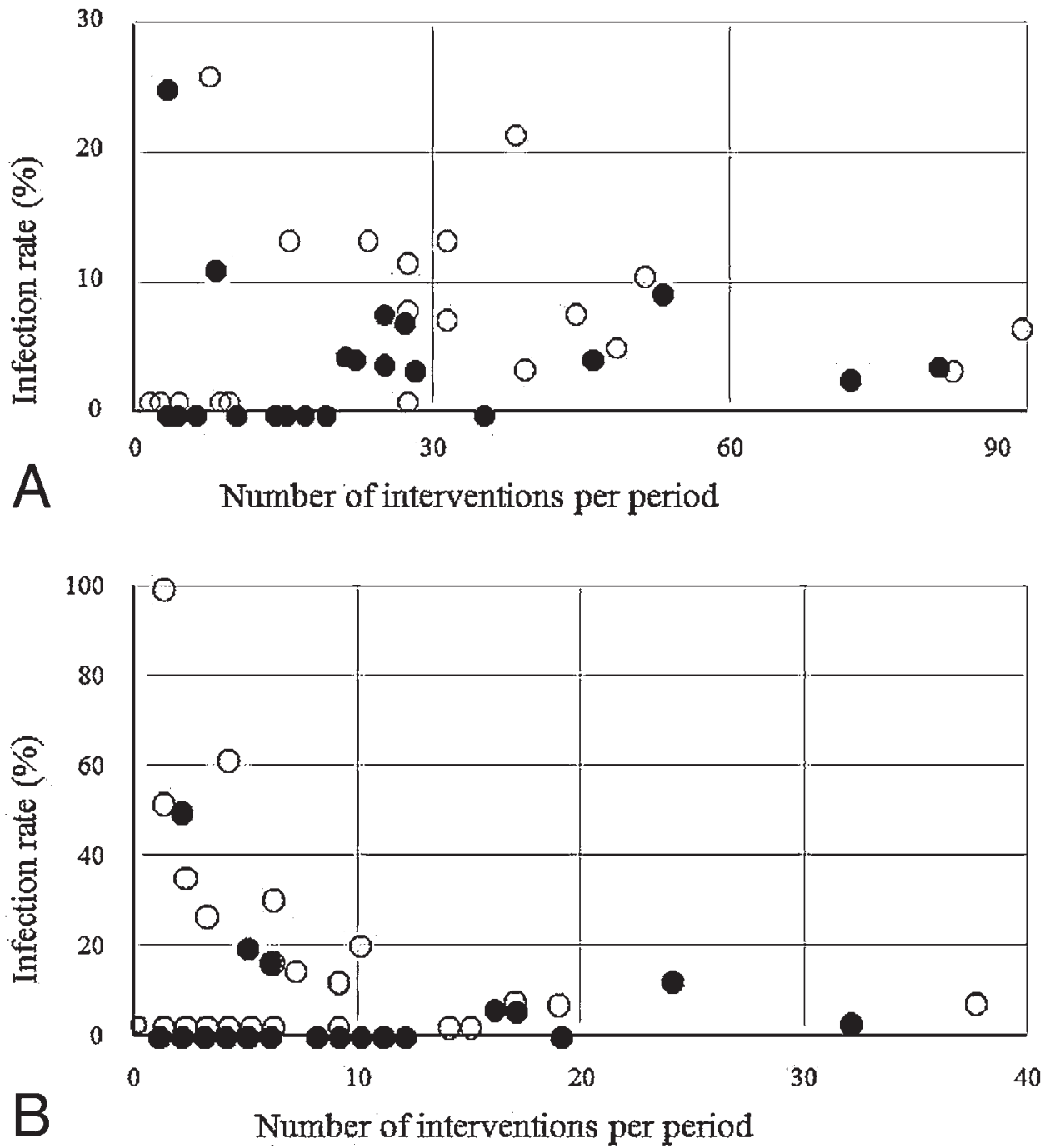

FIG. 2. Correlation between the overall number of operations performed by an individual (plotted on the x-axis) and his or her cumulative infection rate (plotted on the y-axis). Every dot indicates an individual surgeon (A) or technical operation assistant (B), with open circles showing the pre-IPB period and full circles the post-IPB period.

In our study, the introduction of the IPB mainly decreased SSI rates for junior faculty ( $14.6 \%$ vs $4.3 \%)$, while SSI rates remained stable and low in senior faculty $(4.5 \%$ vs $3.3 \%$ ). Comparing the number of operations performed with the overall infection rate per person (Fig. 2), IPB had the greatest impact in less experienced surgeons and technical operation assistants, who presumably need standardization the most.

The IPB enforced conventional training but did not include standardized individual coaching. In the literature, individual coaching has demonstrated a quantifiable positive impact not only on technical skills, but also on learners' perceptions and attitudes. ${ }^{9,32}$ However, coaching has also been seen as a challenge to the surgical culture, complicating its introduction in clinical routine. ${ }^{35}$ Because clinical surrogates of gentle tissue handling, such as the proportion of postoperative bleeding $(6.5 \%$ vs $7.1 \%)$ or the use of hemostatic agents $(59.3 \%$ vs $59.5 \%)$, did not show an improvement post-IPB, we lack evidence of improved sur- gical skills or increased awareness of bleeding risks after the implementation of the bundle.

\section{Study Strengths and Limitations}

The strengths of our study include the high number of unselected patients with a broad range of interventions, high follow-up rates, and the extensive collection of risk factors for SSI.

Our study has several limitations. The retrospective design of the study results in reporting bias. Second, the low number of end points reduces the statistical power to identify risk factors for SSI. Third, with a large number of baseline characteristics, significant differences may be due to chance alone. Fourth, differences in baseline characteristics between the pre- and post-IPB period may have influenced the outcome. We therefore performed multivariate sensitivity analyses including all parameters with significant differences or trends for differences at baseline. Remarkably, none of these parameters altered the significant 
effect of the IPB on SSI. Fifth, CSF leakage, an established risk factor for SSI in several reports, ${ }^{21,22}$ was not recorded in our study. Furthermore, we do not have compliance data for each of the 10 individual interventions of the IPB. Novel concepts such as the introduction of hair clippers or the creation of a specialized technical operation assistant team reached $100 \%$ compliance. Strict alcohol-based skin disinfection improved from $93 \%$ to $97 \%(p=0.04)$, whereas the proportion of adequate SAP remained unchanged ( $82 \%$ vs $81 \%, p=0.86)$. In contrast, behavioral changes could not be quantified, due to both a lack of resources for monitoring and the difficulty of measuring attitudes. Barrier precautions were regularly controlled in the operating theater with direct feedback to the staff, but not collected systematically. Also, the Hawthorne effect, i.e., increased awareness of the importance of infection control only by being part of an intervention study, presumably increased the effect of the individual interventions..$^{10}$ Lastly, changes in the composition of the surgeons' and technical assistants' teams may have influenced SSI dynamics in addition to the IPB. However, there were neither statistically significant associations of SSI with individuals nor abnormal fluctuation rates. The exclusive inclusion of cranial neurosurgery in the study limits the applicability of our results to neurosurgical procedures in general.

\section{Conclusions}

The implementation of an IPB was followed by a significant reduction of SSI in cranial neurosurgery. The overall effect exceeded the measurable effect of the 10 individual interventions included in the bundle, suggesting that increasing the awareness of the importance of infection control by standardized surveillance and feedback is key. Postoperative bleeding was the most important modifiable risk factor for infection and should be addressed by meticulous hemostasis rather than use of hemostatic agents bearing a risk for biofilm infections. Furthermore, the data underline both the importance of surgical experience as well as thorough supervision and coaching of younger colleagues.

\section{Acknowledgments}

We thank the Department of Anesthesiology for their efforts while implementing the prevention bundle into the daily routine and their readiness to be monitored. The study was supported by a grant of the Research Council of the Kantonsspital Aarau, Switzerland.

\section{References}

1. Abu Hamdeh S, Lytsy B, Ronne-Engström E: Surgical site infections in standard neurosurgery procedures - a study of incidence, impact and potential risk factors. Br J Neurosurg 28:270-275, 2014

2. Altemeier WA, American College of Surgeons: Manual on Control of Infection in Surgical Patients, ed 2. Philadelphia: JB Lippincott, 1984

3. Anderson DJ, Podgorny K, Berríos-Torres SI, Bratzler DW, Dellinger EP, Greene L, et al: Strategies to prevent surgical site infections in acute care hospitals: 2014 update. Infect Control Hosp Epidemiol 35 (Suppl 2):S66-S88, 2014

4. Astagneau P, Rioux C, Golliot F, Brücker G: Morbidity and mortality associated with surgical site infections: results from the 1997-1999 INCISO surveillance. J Hosp Infect 48:267-274, 2001

5. Barker FG II: Efficacy of prophylactic antibiotics for craniotomy: a meta-analysis. Neurosurgery 35:484-492, 1994

6. Berríos-Torres SI, Umscheid CA, Bratzler DW, Leas B, Stone EC, Kelz RR, et al: Centers for Disease Control and Prevention Guideline for the Prevention of Surgical Site Infection, 2017. JAMA Surg 152:784-791, 2017

7. Birgand G, Saliou P, Lucet JC: Influence of staff behavior on infectious risk in operating rooms: what is the evidence? Infect Control Hosp Epidemiol 36:93-106, 2015

8. Birkmeyer JD, Finks JF, O'Reilly A, Oerline M, Carlin AM, Nunn AR, et al: Surgical skill and complication rates after bariatric surgery. N Engl J Med 369:1434-1442, 2013

9. Bonrath EM, Dedy NJ, Gordon LE, Grantcharov TP: Comprehensive surgical coaching enhances surgical skill in the operating room: a randomized controlled trial. Ann Surg 262:205-212, 2015

10. Borer A, Gilad J, Meydan N, Riesenberg K, Schlaeffer F, Alkan M, et al: Impact of active monitoring of infection control practices on deep sternal infection after open-heart surgery. Ann Thorac Surg 72:515-520, 2001

11. Buffet-Bataillon S, Haegelen C, Riffaud L, Bonnaure-Mallet M, Brassier G, Cormier M: Impact of surgical site infection surveillance in a neurosurgical unit. J Hosp Infect 77:352355,2011

12. Chen LF, Vander Weg MW, Hofmann DA, Reisinger HS: The Hawthorne Effect in infection prevention and epidemiology. Infect Control Hosp Epidemiol 36:1444-1450, 2015

13. Coello R, Charlett A, Wilson J, Ward V, Pearson A, Borriello $P$ : Adverse impact of surgical site infections in English hospitals. J Hosp Infect 60:93-103, 2005

14. Culver DH, Horan TC, Gaynes RP, Martone WJ, Jarvis WR, Emori TG, et al: Surgical wound infection rates by wound class, operative procedure, and patient risk index. Am J Med 91 (3B):152S-157S, 1991

15. Dashti SR, Baharvahdat H, Spetzler RF, Sauvageau E, Chang SW, Stiefel MF, et al: Operative intracranial infection following craniotomy. Neurosurg Focus 24(6):E10, 2008

16. Davies BM, Jones A, Patel HC: Implementation of a care bundle and evaluation of risk factors for surgical site infection in cranial neurosurgery. Clin Neurol Neurosurg 144:121-125, 2016

17. Davies BM, Jones A, Patel HC: Surgical-site infection surveillance in cranial neurosurgery. Br J Neurosurg 30:35-37, 2016

18. Horan TC, Andrus M, Dudeck MA: CDC/NHSN surveillance definition of health care-associated infection and criteria for specific types of infections in the acute care setting. Am J Infect Control 36:309-332, 2008

19. Jafari MD, Jafari F, Young MT, Smith BR, Phalen MJ, Nguyen NT: Volume and outcome relationship in bariatric surgery in the laparoscopic era. Surg Endosc 27:4539-4546, 2013

20. Kanamori H, Weber DJ, DiBiase LM, Sickbert-Bennett EE, Brooks R, Teal L, et al: Longitudinal trends in all healthcareassociated infections through comprehensive hospital-wide surveillance and infection control measures over the past 12 years: substantial burden of healthcare-associated infections outside of intensive care units and "other" types of infection. Infect Control Hosp Epidemiol 36:1139-1147, 2015

21. Korinek AM: Risk factors for neurosurgical site infections after craniotomy: a prospective multicenter study of 2944 patients. The French Study Group of Neurosurgical Infections, the SEHP, and the C-CLIN Paris-Nord. Neurosurgery 41:1073-1081, 1997

22. Korinek AM, Golmard JL, Elcheick A, Bismuth R, van Effenterre R, Coriat P, et al: Risk factors for neurosurgical site infections after craniotomy: a critical reappraisal of antibiotic 
prophylaxis on 4,578 patients. Br J Neurosurg 19:155-162, 2005

23. Le C, Guppy KH, Axelrod YV, Hawk MW, Silverthorn J, Inacio MC, et al: Lower complication rates for cranioplasty with peri-operative bundle. Clin Neurol Neurosurg 120:4144, 2014

24. Lefebvre A, Saliou P, Lucet JC, Mimoz O, Keita-Perse O, Grandbastien B, et al: Preoperative hair removal and surgical site infections: network meta-analysis of randomized controlled trials. J Hosp Infect 91:100-108, 2015

25. Lieber BA, Appelboom G, Taylor BE, Lowy FD, Bruce EM, Sonabend AM, et al: Preoperative chemotherapy and corticosteroids: independent predictors of cranial surgical-site infections. J Neurosurg 125:187-195, 2016

26. Liu H, Dong X, Yin Y, Chen Z, Zhang J: Reduction of surgical site infections after cranioplasty with perioperative bundle. J Craniofac Surg 28:1408-1412, 2017

27. Ma N, Cameron A, Tivey D, Grae N, Roberts S, Morris A: Systematic review of a patient care bundle in reducing staphylococcal infections in cardiac and orthopaedic surgery. ANZ J Surg 87:239-246, 2017

28. Maiwald M, Chan ESY: The forgotten role of alcohol: a systematic review and meta-analysis of the clinical efficacy and perceived role of chlorhexidine in skin antisepsis. PLoS One 7:e44277, 2012

29. Mangram AJ, Horan TC, Pearson ML, Silver LC, Jarvis WR: Guideline for prevention of surgical site infection, 1999. Infect Control Hosp Epidemiol 20:250-280, 1999

30. Martin ET, Kaye KS, Knott C, Nguyen H, Santarossa M, Evans R, et al: Diabetes and risk of surgical site infection: a systematic review and meta-analysis. Infect Control Hosp Epidemiol 37:88-99, 2016

31. McClelland S III, Hall WA: Postoperative central nervous system infection: incidence and associated factors in 2111 neurosurgical procedures. Clin Infect Dis 45:55-59, 2007

32. Min H, Morales DR, Orgill D, Smink DS, Yule S: Systematic review of coaching to enhance surgeons' operative performance. Surgery 158:1168-1191, 2015

33. Misteli H, Weber WP, Reck S, Rosenthal R, Zwahlen M, Fueglistaler P, et al: Surgical glove perforation and the risk of surgical site infection. Arch Surg 144:553-558, 2009

34. Munday GS, Deveaux P, Roberts H, Fry DE, Polk HC: Impact of implementation of the Surgical Care Improvement Project and future strategies for improving quality in surgery. Am J Surg 208:835-840, 2014

35. Mutabdzic D, Mylopoulos M, Murnaghan ML, Patel P, Zilbert N, Seemann N, et al: Coaching surgeons: Is culture limiting our ability to improve? Ann Surg 262:213-216, 2015

36. Perez P, Holloway J, Ehrenfeld L, Cohen S, Cunningham L, Miley GB, et al: Door openings in the operating room are associated with increased environmental contamination. Am J Infect Control 46:954-956, 2018

37. Reames BN, Ghaferi AA, Birkmeyer JD, Dimick JB: Hospital volume and operative mortality in the modern era. Ann Surg 260:244-251, 2014

38. Sneh-Arbib O, Shiferstein A, Dagan N, Fein S, Telem L, Muchtar E, et al: Surgical site infections following craniotomy focusing on possible post-operative acquisition of infec- tion: prospective cohort study. Eur J Clin Microbiol Infect Dis 32:1511-1516, 2013

39. Strahm C, Albrich WC, Zdravkovic V, Schöbi B, Hildebrandt $\mathrm{G}$, Schlegel M: Infection rate after cranial neurosurgical procedures: a prospective single-center study. World Neurosurg 111:e277-e285, 2018

40. Tanner J, Padley W, Assadian O, Leaper D, Kiernan M, Edmiston C: Do surgical care bundles reduce the risk of surgical site infections in patients undergoing colorectal surgery? A systematic review and cohort meta-analysis of 8,515 patients. Surgery 158:66-77, 2015

41. Troillet N, Aghayev E, Eisenring MC, Widmer AF: First results of the Swiss National Surgical Site Infection Surveillance Program: Who seeks shall find. Infect Control Hosp Epidemiol 38:697-704, 2017

42. Umscheid CA, Mitchell MD, Doshi JA, Agarwal R, Williams $\mathrm{K}$, Brennan PJ: Estimating the proportion of healthcareassociated infections that are reasonably preventable and the related mortality and costs. Infect Control Hosp Epidemiol 32:101-114, 2011

43. Weber WP, Mujagic E, Zwahlen M, Bundi M, Hoffmann H, Soysal SD, et al: Timing of surgical antimicrobial prophylaxis: a phase 3 randomised controlled trial. Lancet Infect Dis 17:605-614, 2017

44. Zimlichman E, Henderson D, Tamir O, Franz C, Song P, Yamin CK, et al: Health care-associated infections: a metaanalysis of costs and financial impact on the US health care system. JAMA Intern Med 173:2039-2046, 2013

45. Zywot A, Lau CSM, Stephen Fletcher H, Paul S: Bundles prevent surgical site infections after colorectal surgery: meta-analysis and systematic review. J Gastrointest Surg 21:1915-1930, 2017

\section{Disclosures}

The authors report no conflict of interest concerning the materials or methods used in this study or the findings specified in this paper.

\section{Author Contributions}

Conception and design: Fux, Fandino. Acquisition of data: Rubeli, Mueller, Bartlomé. Analysis and interpretation of data: Fux, Rubeli, D'Alonzo, Conen, Fandino. Drafting the article: Fux, Rubeli. Critically revising the article: Fux, Rubeli, D’Alonzo, Conen, Fandino. Reviewed submitted version of manuscript: all authors. Approved the final version of the manuscript on behalf of all authors: Fux. Statistical analysis: Fux, Rubeli. Administrative/ technical/material support: Fux, D’Alonzo, Mueller, Bartlomé, Fankhauser, Bucheli, Fandino. Study supervision: Fux.

\section{Correspondence}

Christoph A. Fux: Kantonsspital Aarau, Switzerland. christoph. fux@ksa.ch. 